\title{
TITLE:
}

\section{Low-frequency dielectric dispersion of bacterial cell suspensions.}

$\operatorname{AUTHOR}(S)$ :

Asami, Koji

CITATION:

Asami, Koji. Low-frequency dielectric dispersion of bacterial cell suspensions.. Colloids and surfaces. B, Biointerfaces 2014, 119: 1-5

ISSUE DATE:

2014-07-01

URL:

http://hdl.handle.net/2433/187789

\section{RIGHT:}

(c) 2014 Elsevier B.V.; This is not the published version. Please cite only the published version.; この論文は出版社版でありません。引用の際に は出版社版をご確認ご利用ください。 
Colloids and Surfaces B: Biointerfaces 119 (2014) 1-5

\title{
Low-frequency dielectric dispersion of bacterial cell suspensions
}

Koji Asami* $^{*}$

Institute for Chemical Research, Kyoto University, Uji, Kyoto 611-0011, Japan

*Corresponding author, Tel: +81-774-38-3081; Fax: +81-774-38-3084;

e-mail: asami@e.kuicr.kyoto-u.ac.jp

\begin{abstract}
Dielectric spectra of Escherichia coli cells suspended in 0.1-10 $\mathrm{mM} \mathrm{NaCl}$ were measured over a frequency range of $10 \mathrm{~Hz}$ to $10 \mathrm{MHz}$. Low-frequency dielectric dispersion, so-called the $\alpha$-dispersion, was found below $10 \mathrm{kHz}$ in addition to the $\beta$-dispersion, due to interfacial polarization, appearing above $100 \mathrm{kHz}$. When the cells were killed by heating at $60{ }^{\circ} \mathrm{C}$ for $30 \mathrm{~min}$, the $\beta$-dispersion disappeared completely, whereas the $\alpha$-dispersion was little influenced. This suggests that the plasma (or inner) membranes of the dead cells are no longer the permeability barrier to small ions, and that the $\alpha$-dispersion is not related to the membrane potential due to selective membrane permeability of ions. The intensity of the $\alpha$-dispersion depended on both of the $\mathrm{pH}$ and ionic strength of the external medium, supporting the model that the $\alpha$-dispersion results from the deformation of the ion clouds formed outside and inside the cell wall containing charged residues.
\end{abstract}

Keywords: Dielectric dispersion; Bacteria; Counterion polarization; Cell death; Membrane potential; Cell wall 


\section{Introduction}

Bacterial cells have been studied by dielectric spectroscopy to understand the electrical and structural properties of the plasma membrane, cell wall and cytoplasm. Fricke et al. [1] first reported dielectric dispersion of Escherichia coli cell suspensions in the frequency range of $100 \mathrm{kHz}$ to $10 \mathrm{MHz}$, and suggested the presence of the insulating plasma membrane, of which specific capacitance was estimated to be 0.7 $\mu \mathrm{F} / \mathrm{cm}^{2}$. The dielectric dispersion, which is referred to as the $\beta$-dispersion, is due to interfacial polarization [2-4]. Carstensen and coworkers [5-8] subsequently revealed that bacterial cells have a conducting cell wall outside the insulating plasma membrane, and modeled the cells as a sphere covered with two concentric shells that correspond to the plasma membrane and the cell wall. The conductivity of the cell wall in low salt media is dominated by the mobile counterions of fixed charges in the cell wall. The spherical cell model was extended to ellipsoidal cell models, which were applied to the $\beta$-dispersion of rod-shaped $E$. coli cells [9, 10].

Dielectric dispersion, termed the $\alpha$-dispersion, was found for M. Lysodeikticus cells at frequencies below $10 \mathrm{kHz}[11,12]$. The $\alpha$-dispersion, however, has not been reported except a few studies [13-15] because electrode polarization (EP) effects interfere with its accurate measurement. The origin of the $\alpha$-dispersion is therefore still a controversial issue although the $\alpha$-dispersion has been believed to be caused by the deformation of the counterion cloud outside the charged cell surface, i.e., counterion polarization (CP), from analogy with the low-frequency (LF) dispersion of charged colloids. Schwarz [16] proposed a condensed counterion model to interpret the LF dispersion of charged insulating particles suspended in electrolyte solutions. In the model, counterions move along the particle surface without exchanging with ions in the bulk phase. Einolf and Carstensen [12] extended the Schwarz model to analyze the $\alpha$-dispersion of bacterial cells by taking into account both counterion layers inside and outside the cell wall. Afterward, Dukhin and Shilove [17] proposed a different model that includes diffusion of ions in the bulk phase and exchange of ions between the electrical double layer and the bulk phase. Many theoretical advances have been made along the Dukhin-Shilove model, as described in a review of Grosse and Delgado [18]. Grosse and Zimmerman [19] have extended the Dukhin-Shilove model to lipid vesicles and biological cells, which are modeled as a sphere covered with a single shell possessing charged surfaces, and have obtained an analytical solution that enables us to simulate the whole dielectric spectrum including the $\alpha$ - and the $\beta$-dispersions. Further, numerical simulation has been carried out with the cell model that has a porous charged wall outside the plasma membrane [20]. 
Recently, similar but alternative models have been proposed to interpret both of the $\alpha$ - and the $\beta$-dispersions of cell suspensions [21-26]. The models focus on the membrane potential evoked in living cells. Charges are accumulated at the membrane interfaces according to the potential difference across the membrane and move on the cell surface when an electric field is applied to the cell. The charge migration gives rise large polarization at low frequencies, resulting in the $\alpha$-dispersion. The theoretical models imply that the membrane potential can be determined from the $\alpha$-dispersion. Indeed, attempts to determine the membrane potential of $E$. coli cells were made [14, 15]. Experimental evidence, however, is insufficient to support the relationships between the membrane potential and the $\alpha$-dispersion.

In this article, the origin of the $\alpha$-dispersion in $E$. coli cell suspensions has been studied. Dielectric measurement has been carried out not only to determine whether the $\alpha$-dispersion is associated with the membrane potential in living cells but also to evaluate the contributions of the density of charged groups in the cell wall and the ionic strength of the external medium.

\section{Materials and methods}

\subsection{Cultivation and preparation of E. coli cells}

A strain (K12) of E. coli was obtained from the Institute for Fermentation, Osaka. Cells were grown in a culture medium containing $10 \%$ polypeptone, $2 \%$ yeast extract and $1 \% \mathrm{MgSO}_{4} \cdot 7 \mathrm{H}_{2} \mathrm{O}$ at $30{ }^{\circ} \mathrm{C}$ under aerobic conditions and were collected in the early stationary phase. The cells were washed at least twice in $1 \mathrm{mM} \mathrm{NaCl}$.

Heat-treated cells were obtained by incubating intact cells in $1 \mathrm{mM} \mathrm{NaCl}$ at $60{ }^{\circ} \mathrm{C}$ for $30 \mathrm{~min}$. After the heat treatment, the cells were washed in $1 \mathrm{mM} \mathrm{NaCl}$ and were used for examining the effects of the $\mathrm{pH}$ and $\mathrm{NaCl}$ concentration of the external medium. The $\mathrm{pH}$ of the cell suspensions was varied between 4 and 10 by titrating with $0.1 \mathrm{M} \mathrm{HCl}$ and $0.1 \mathrm{M} \mathrm{NaOH}$. The $\mathrm{NaCl}$ concentration of the medium was changed from 0.1 to 4 $\mathrm{mM}$.

\subsection{Dielectric spectroscopy}

Dielectric measurements have been carried out with a 4192A Impedance Analyzer over a frequency range of $10 \mathrm{~Hz}$ to $10 \mathrm{MHz}$. A conventional parallel plate capacitor similar to that described previously [27] was used as a measurement cell having a cylindrical sample cavity ( $4 \mathrm{~mm}$ in diameter and $4 \mathrm{~mm}$ in length) with platinum-black electrodes that were carefully prepared to reduce the EP effect. The measurement cell was filled with a cell suspension and its admittance was measured at $24-26^{\circ} \mathrm{C}$. Using 
the stray capacitance and the cell constant of the measurement cell, the admittance was converted into the relative complex permittivity $\varepsilon^{*}$ of the suspension defined as $\varepsilon^{*}=\varepsilon+\kappa /\left(\mathrm{j} 2 \pi f \varepsilon_{0}\right)$, where $\varepsilon$ is the relative permittivity, $\kappa$ is the conductivity, $f$ is the frequency of the applied ac field, $\varepsilon_{0}$ is the permittivity of vacuum and $\mathrm{j}$ is the imaginary unit.

\section{Results and discussion}

\subsection{Dielectric spectra of E. coli cell suspensions}

Dielectric spectra were measured for cells suspended in 1-10 $\mathrm{mM} \mathrm{NaCl}$ solutions at a volume fraction of 0.1-0.2. The osmolarity of the medium was not adjusted because the dielectric spectra were not influenced by addition of $0.3 \mathrm{M}$ mannitol. Figure 1 shows the relative permittivity of the cell suspensions measured at the same cell concentration. The low-frequency (LF) and the high-frequency (HF) dispersions, which correspond to the $\alpha$ - and the $\beta$-dispersions, respectively, are clearly seen although the EP effect covers the $\mathrm{LF}$ dispersion partly for $1 \mathrm{mM} \mathrm{NaCl}$ and mostly for $10 \mathrm{mM} \mathrm{NaCl}$. The dielectric spectra including the EP effect were well represented by

$$
\varepsilon^{*}=\varepsilon_{\mathrm{h}}+\frac{\Delta \varepsilon_{\mathrm{L}}}{1+\left(j f / f_{\mathrm{L}}\right)^{\beta_{\mathrm{L}}}}+\frac{\Delta \varepsilon_{\mathrm{H}}}{1+\left(j f / f_{\mathrm{H}}\right)^{\beta_{\mathrm{H}}}}+\frac{\kappa_{\mathrm{l}}}{j 2 \pi f \varepsilon_{0}}+A f^{-m}
$$

which contains two Cole-Cole relaxation terms (subscripts $\mathrm{L}$ and $\mathrm{H}$ refer to the $\mathrm{LF}$ and the HF relaxation processes) and the EP term with constants $A$ and $m$ [28]. $\Delta \varepsilon_{\mathrm{x}}, f_{\mathrm{x}}$ and $\beta_{\mathrm{x}}$ $(\mathrm{x}=\mathrm{L}$ and $\mathrm{H})$ are the intensity, characteristic frequency and broadening factor of the Cole-Cole relaxation, respectively. $c_{\mathrm{h}}$ and $\kappa$ are the HF limit of the relative permittivity and the LF limit of the conductivity, respectively. The values of $\varepsilon_{\mathrm{h}}, \Delta \varepsilon_{\mathrm{L}}, f_{\mathrm{L}}, \beta_{\mathrm{L}}, \Delta \varepsilon_{\mathrm{H}}, f_{\mathrm{H}}$, $\beta_{\mathrm{H}}, A$ and $m$ in Eq. (1) were determined by the non-linear least squares method to minimize the residual $\chi^{2}$

$$
\chi^{2}=\sum_{i}\left\{\log _{10} \operatorname{Re}\left[\varepsilon_{\mathrm{ob}}^{*}\left(f_{i}\right)\right]-\log _{10} \operatorname{Re}\left[\varepsilon_{\mathrm{th}}^{*}\left(f_{i}\right)\right]\right\}^{2},
$$

where $\operatorname{Re}\left[\varepsilon^{*}{ }_{\mathrm{ob}}\left(f_{\mathrm{i}}\right)\right]$ and $\operatorname{Re}\left[\mathcal{\varepsilon}_{\mathrm{th}}^{*}\left(f_{\mathrm{i}}\right)\right]$ are the real parts of the observed and theoretical complex permittivities, respectively, and $f_{i}$ is the $i$-th frequency. The best-fit parameters are listed in Table 1 . The values of $\kappa$ and the medium conductivity $\kappa_{\mathrm{a}}$ were estimated from the conductivities of the cell suspension and the external medium at $0.1-1 \mathrm{kHz}$, respectively. 
The $\Delta \varepsilon_{\mathrm{H}}$ of the HF dispersion increased with increasing the $\mathrm{NaCl}$ concentration $c_{\mathrm{a}}$ of the medium (see the inset of Fig. 1 and Table 1 ). The ratio $\kappa_{1} / \kappa_{\mathrm{a}}$ increased as decreasing $c_{\mathrm{a}}$, suggesting that the effective conductivity $\kappa_{\mathrm{p}}$ of the cell remains a high level while $\kappa_{\mathrm{a}}$ decreases. The high $\kappa_{\mathrm{p}}$ results from the high cell wall conductivity that is due to the mobile counterions of the fixed charges in the cell wall [8]. The presence of the conducting cell wall reduces the charging of the plasma membrane, resulting in the decrease in $\Delta \varepsilon_{\mathrm{H}}[4,9]$. The $f_{\mathrm{H}}$ increased with $\kappa_{\mathrm{a}}$, which is interpreted in terms of interfacial polarization [9].

The values of $\Delta \varepsilon_{\mathrm{L}}$ and $f_{\mathrm{L}}$ of the LF dispersion were unchanged between $1 \mathrm{mM}$ and 3 $\mathrm{mM}$. Above $6 \mathrm{mM}$, those include large errors in estimation owing to the EP effect, which makes quantitative discussion difficult. The value of $\beta_{\mathrm{L}}$ was about 0.85 and was comparable to that obtained for the $\alpha$-dispersion of $M$. lysodeikticus cells $\left(\beta_{\mathrm{L}} \approx 0.8\right)$ [11]. The value of $\beta_{\mathrm{L}}$ was smaller than that of $\beta_{\mathrm{H}}$, indicating that the LF dispersion distributed over a wider frequency range than the HF dispersion.

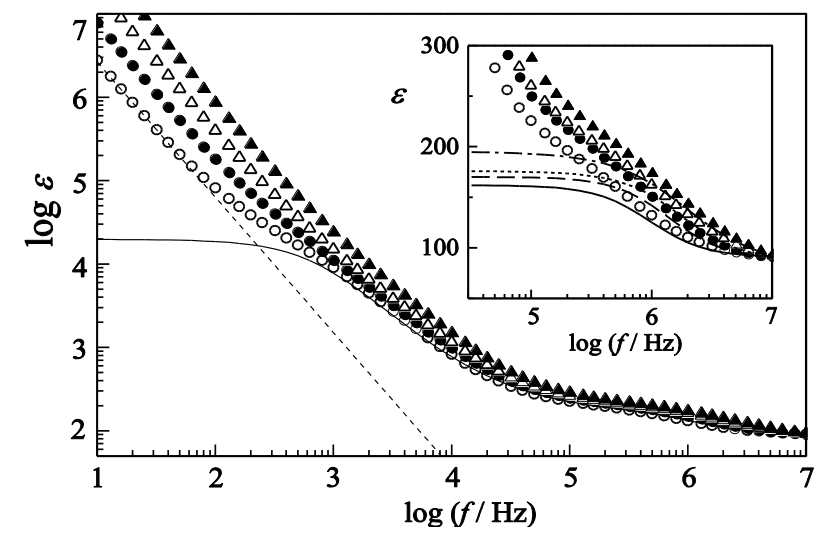

Fig. 1 Frequency $f$ dependence of the relative permittivity $\varepsilon$ of $E$. coli cells suspended in 1 (०), 3 $(\bullet), 6(\Delta)$ and $10(\Delta) \mathrm{mM} \mathrm{NaCl}$. The cell suspensions were prepared to have the same cell concentration. The best-fit curve (solid line) for the data with $1 \mathrm{mM} \mathrm{NaCl}$ is shown separately from the EP effect (broken line). Inset: an expanded view of the HF dispersion with the best-fit curves for the data with $1 \mathrm{mM}$ (solid line), $3 \mathrm{mM}$ (broken line), $6 \mathrm{mM}$ (dotted line) and $10 \mathrm{mM}$ (dashed-dotted line).

Table 1 Dielectric relaxation parameters determined from the dielectric spectra shown in Fig. 1.

\begin{tabular}{cccccccccc}
\hline$c_{\mathrm{a}} / \mathrm{mM}$ & $\varepsilon_{\mathrm{h}}$ & $\Delta \varepsilon_{\mathrm{H}}$ & $f_{\mathrm{H}} / \mathrm{MHz}$ & $\beta_{\mathrm{H}}$ & $\Delta \varepsilon \mathrm{L}$ & $f_{\mathrm{L}} / \mathrm{kHz}$ & $\beta_{\mathrm{L}}$ & $\kappa / \mathrm{mS} \mathrm{m}^{-1}$ & $\kappa / \kappa_{\mathrm{a}}$ \\
\hline 1 & 91 & 71 & 0.97 & 0.98 & 19700 & 0.73 & 0.86 & 23 & 1.74 \\
3 & 89 & 81 & 1.40 & 0.97 & 20800 & 0.69 & 0.84 & 37 & 1.09
\end{tabular}




\begin{tabular}{rrrrrrrrrr}
6 & 86 & 89 & 1.78 & 0.94 & 17200 & 1.13 & 0.86 & 70 & 0.97 \\
10 & 81 & 115 & 1.99 & 0.85 & 9700 & 1.83 & 0.84 & 108 & 0.94 \\
\hline
\end{tabular}

\subsection{Effects of heat treatment}

Several authors [21-26] proposed models in which the potential difference across the membrane plays an important role in the LF dispersion. The membrane potential is mainly resulted from the diffusion of specific ions along their concentration gradient produced by active transport, diminishing in dead cells. To examine whether the membrane potential takes part in the LF dispersion, the dielectric spectra of live cells were compared, at the same cell concentration, with those of cells killed by heating at $60{ }^{\circ} \mathrm{C}$ for $30 \mathrm{~min}$ (Fig. 2). The heat treatment resulted in ion leakage from the cells, indicating the loss of the membrane barrier to ions. It is well known that heat treatment above $60{ }^{\circ} \mathrm{C}$ causes the loss of the membrane integrity and the membrane potential of $E$. coli cells [29, 30].

The HF dispersion disappeared completely in the dead cells, whereas the LF dispersion was independent of whether cells are alive or dead. The disappearance of the HF dispersion suggests that the plasma membranes are not polarized by an external electric field because ions are highly permeable into the membranes of the dead cells. Indeed, the numerical simulation shown in Fig. 5 indicates that, when the LF dispersion disappears, the conductivity of the membrane is more than $3 \times 10^{-4} \mathrm{~S} / \mathrm{m}$, which corresponds to that of an aqueous solution of $0.03 \mathrm{mM} \mathrm{NaCl}$. This makes the presence of the ion concentration gradient across the membrane in the dead cells very unlikely. The diffusion potential, therefore, is not related to the LF dispersion.

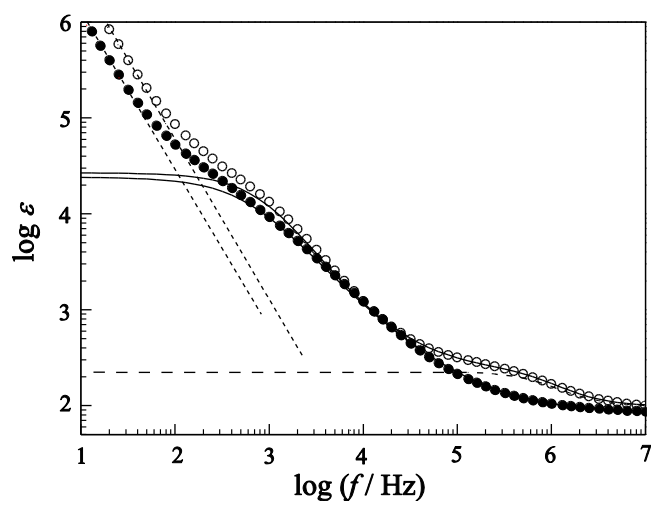

Fig. 2 Frequency $f$ dependence of the relative permittivity $\varepsilon$ for intact $(\circ)$ and heat-treated $(\bullet)$ cells suspended in $1 \mathrm{mM} \mathrm{NaCl}$. The suspensions are prepared to have the same cell concentration. The solid lines are the best-fit curves calculated from Eq. (1), excluding the EP 
effect (dotted line). The HF dispersion (broken line) in intact cells is not seen in dead cells.

\subsection{Effects of medium $p H$ and ionic strength on the LF dispersion}

Since the LF dispersion is not influenced by whether cells are alive or dead, effects of the $\mathrm{pH}$ and $c_{\mathrm{a}}$ of the medium on the LF dispersion have been examined with heat-treated cells that are free from the ion leakage associated with the metabolic activities of the live cells.

The $\mathrm{pH}$ of the suspensions of heat-treated cells in $1 \mathrm{mM} \mathrm{NaCl}$ was adjusted between 4 and 10 by titrating with $0.1 \mathrm{M} \mathrm{HCl}$ or $0.1 \mathrm{M} \mathrm{NaOH}$. Dielectric spectra of the cell suspensions were compared at the same cell concentration. The values of $\Delta \varepsilon \mathrm{L}$ determined at different $\mathrm{pH}$ are normalized at $\mathrm{pH}$ 6.9-7.1, and are plotted against the $\mathrm{pH}$ in Fig. 3a. The $\Delta \varepsilon \mathrm{L}$ decreased as the $\mathrm{pH}$ decreased from 10 to 4 to be zero at $\mathrm{pH} 3-4$, where isoelectric points were reported for many bacteria and isolated cell walls [31]. The $\Delta \varepsilon \mathrm{L}-\mathrm{pH}$ relationships are similar to the acid-base titration curves of $E$. coli suspensions [32], suggesting that $\Delta \varepsilon_{\mathrm{L}}$ is proportional to the density of net charges on the cell surface and/or within the cell wall.

Dielectric spectra have been measured by varying $c_{\mathrm{a}}$ from $0.1 \mathrm{mM}$ to $4 \mathrm{mM}$ at $\mathrm{pH}$ 6.5-6.8, and the $\Delta \varepsilon$, which is normalized at $1 \mathrm{mM}$, are shown in Fig. 3b. The $\Delta \varepsilon \mathrm{L}$ increased with $c_{\mathrm{a}}$ to have a maximum at $2 \mathrm{mM}$ and then decreased.
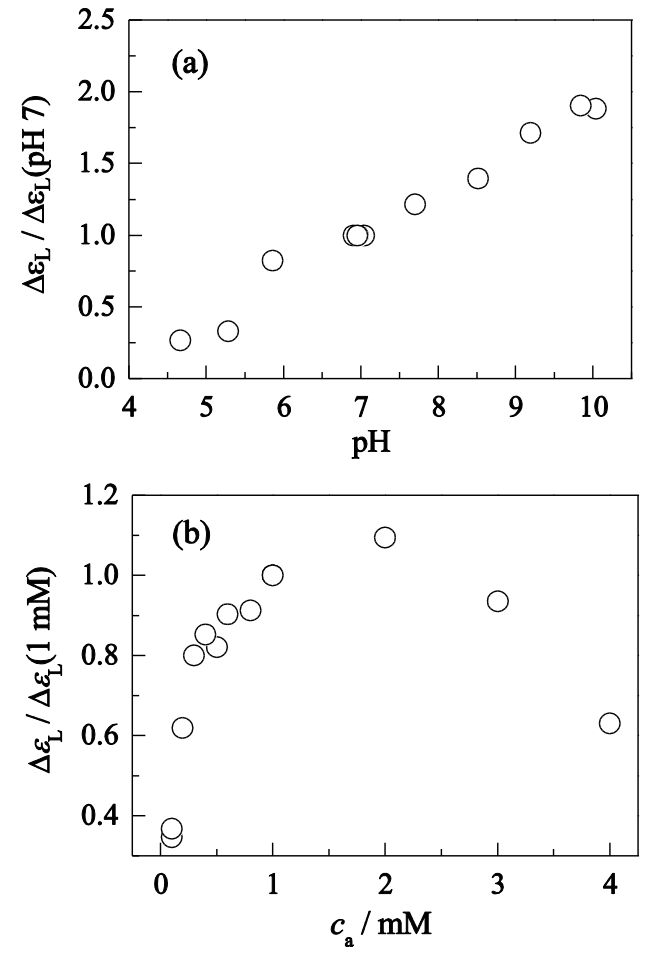
Fig. 3 Effects of (a) the $\mathrm{pH}$ and (b) $\mathrm{NaCl}$ concentration $c_{\mathrm{a}}$ of the medium on the intensity $\Delta \varepsilon_{\mathrm{L}}$ of the LF dispersion. $\Delta \varepsilon_{\mathrm{L}}$ is normalized at (a) $\mathrm{pH}$ 6.9-7.1 and at (b) $1 \mathrm{mM}$.

\subsection{Theoretical consideration}

The experimental results suggest that the LF dispersion of $E$. coli cell suspensions is not related to the potential difference across the plasma membrane but to the ion clouds outside and/or inside the cell wall containing charged residues. The significance of the cell wall in the LF dispersion is supported from a previous finding that the LF dispersion for M. lysodeikticus cells is extremely reduced when the cell wall is removed [11]. Hence, the participation of the counterion polarization in the LF dispersion has been evaluated along the Dukhin and Shilove model.

$E$. coli is classified into gram negative bacteria that have the outer membrane and the inner (plasma) membrane. There is a periplasmic layer containing polyelectolytes between the membranes. The outer membrane permeates ions and small biopolymers through porins (pore-forming membrane proteins) and its outer surface has a lipopolysaccharide layer carrying negatively charged groups. The outer membrane and the periplasmic layer constitute the cell wall. As well as the complex morphology, the non-spherical shape of E. coli cells complicates theoretical analysis. Assuming a charged porous layer for the wall, a spherical bacterial cell is simply modeled as a sphere covered with two shells that correspond to the inner membrane and the wall. For this model, however, an analytical solution has not been obtained, and a numerical technique is required to simulate the dielectric spectra of the cell suspensions [20]. Grosse and Zimmerman derived an analytical solution for a more simplified model that is a sphere covered with a single shell carrying surface charges [19]. Under the circumstances, the Grosse-Zimmerman model has been adopted to examine the characteristics of the dielectric dispersion obtained for $E$. coli cell suspensions.

When spherical cells of radius $R_{\mathrm{c}}$ are suspended in a medium of relative complex permittivity $\varepsilon_{\mathrm{a}}{ }^{*}$ at volume fraction $P$, the complex relative permittivity of the cell suspension $\varepsilon^{*}$ is represented by the Wagner equation as

$$
\varepsilon^{*}=\varepsilon_{a}^{*}\left(1+\frac{3 P d^{*}}{1-P d^{*}}\right),
$$

where $d^{*}$ is the dipole coefficient (or the Clausius-Mossotti factor) and $\varepsilon_{\mathrm{a}}^{*}=\varepsilon_{\mathrm{a}}+\kappa_{\mathrm{a}} /\left(\mathrm{j} 2 \pi f \varepsilon_{0}\right)$ with the relative permittivity $\varepsilon_{\mathrm{a}}$ and conductivity $\kappa_{\mathrm{a}}$ of the medium. 
For the case of $P<<1$, Eq. (3) is reduced to $\varepsilon^{*}=\varepsilon_{\mathrm{a}}{ }^{*}\left(1+3 P d^{*}\right)$, which has been adopted by Grosse and Zimmerman. The dipole coefficient includes two terms $d_{\mathrm{L}}{ }^{*}$ and $d_{\mathrm{H}}{ }^{*}$ that are the LF and HF dipole coefficients, respectively, i.e., $d^{*}=d_{\mathrm{L}}{ }^{*}+d_{\mathrm{H}}{ }^{*}$.

The $d_{\mathrm{L}}{ }^{*}$ due to the counterion polarization is given by

$$
d_{\mathrm{L}}^{*}=\Delta d_{\mathrm{L}} \frac{1+\sqrt{2 / S} \sqrt{j 2 \pi f \tau_{\mathrm{L}}}}{1+\sqrt{2 / S} \sqrt{j 2 \pi f \tau_{\mathrm{L}}}+j 2 \pi f \tau_{\mathrm{L}}}+d_{\mathrm{Lh}} .
$$

If, for sake of simplicity, the external medium contains a 1-1 electrolyte of which anion and cation have the same diffusion constant $D$, the quantities $\Delta d_{\mathrm{L}}, \tau_{\mathrm{L}}, d_{\mathrm{Lh}}$ and $S$ in Eq. (4) are given by the simple forms provided in Appendix. Assuming the Gouy-Chapman model for the electrical double layer, the surface charge density $\sigma_{0}$ is related to the zeta potential $\zeta$ by $\sigma_{0}=\sqrt{8 R T \varepsilon_{\mathrm{a}} \varepsilon_{0} c_{\mathrm{a}}} \sinh (F \zeta / 2 R T)$, where $c_{\mathrm{a}}$ is the electrolyte concentration in $\mathrm{mol} \mathrm{m} \mathrm{m}^{-3}$ (or $\mathrm{mM}$ ), $F$ is the Faraday constant, $R$ is the gas constant and $T$ is thermodynamic temperature. The conductivity of the external medium $\kappa_{\mathrm{a}}$ is given by $\kappa_{\mathrm{a}}=2 D F^{2} c_{\mathrm{a}} /(R T)$.

The dipole moment induced at high frequencies is due to interfacial polarization. A cell is modeled as a spherical cytoplasm (of complex relative permittivity $\varepsilon_{1}^{*}$ ) covered with a membrane (of complex relative permittivity $\varepsilon_{\mathrm{m}}{ }^{*}$ ). Taking into account the surface conductance $\lambda$ due to the electrical double layer outside the cell surface, the effective relative complex permittivity of the cell $\varepsilon_{\mathrm{p}}{ }^{*}$ is written as

$$
\varepsilon_{\mathrm{p}}^{*}=\frac{1}{j 2 \pi f \varepsilon_{\mathrm{v}}} \frac{2 \lambda}{R_{\mathrm{c}}}+\varepsilon_{\mathrm{m}}^{*} \frac{\varepsilon_{\mathrm{i}}^{*}+2 \varepsilon_{\mathrm{m}}^{*}+2 v\left(\varepsilon_{\mathrm{i}}^{*}-\varepsilon_{\mathrm{m}}^{*}\right)}{\varepsilon_{\mathrm{i}}^{*}+2 \varepsilon_{\mathrm{m}}^{*}-v\left(\varepsilon_{\mathrm{i}}^{*}-\varepsilon_{\mathrm{m}}^{*}\right)},
$$

where $\varepsilon_{\mathrm{m}}{ }^{*}=\varepsilon_{\mathrm{m}}+\kappa_{\mathrm{m}} /\left(\mathrm{j} 2 \pi f \varepsilon_{0}\right)$ with the relative permittivity $\varepsilon_{\mathrm{m}}$ and conductivity $\kappa_{\mathrm{m}}$ of the membrane, $\varepsilon_{1}^{*}=\varepsilon_{1}+\kappa_{\mathrm{i}} /\left(\mathrm{j} 2 \pi f \varepsilon_{0}\right)$ with the relative permittivity $\varepsilon_{\mathrm{1}}$ and conductivity $\kappa_{\mathrm{1}}$ of the cytoplasm and $v=\left(1-d_{\mathrm{m}} / R_{\mathrm{c}}\right)^{3}$ with the membrane thickness $d_{\mathrm{m}}$. The dipole coefficient $d_{\mathrm{H}}{ }^{*}$ is given by

$$
d_{\mathrm{H}}^{*}=\frac{\varepsilon_{\mathrm{p}}^{*}-\varepsilon_{\mathrm{a}}^{*}}{\varepsilon_{\mathrm{p}}^{*}+2 \varepsilon_{\mathrm{a}}^{*}}
$$


Since the HF limit of $d_{\mathrm{L}}{ }^{*}$ must coincide with the LF limit of $d_{\mathrm{H}}{ }^{*}, \lambda$ becomes

$$
\lambda=\frac{R^{+}+R^{-}}{4} R_{\mathrm{c}} \kappa_{\mathrm{a}},
$$

where $R^{+}$and $R^{-}$are given by Eq. (A5) in Appendix.

The dielectric spectra were calculated using Eqs. (3)-(7) with the parameter values relevant to $E$. coli cells $[9,10]$ and the experimental conditions: $\varepsilon_{\mathrm{a}}=80, \varepsilon_{\mathrm{m}}=5, \varepsilon_{\mathrm{1}}=60$, $\kappa_{\mathrm{i}}=0.2 \mathrm{~S} / \mathrm{m}, d_{\mathrm{m}}=5 \mathrm{~nm}, R_{\mathrm{c}}=1 \mu \mathrm{m}, D=2 \times 10^{-9} \mathrm{~m}^{2} / \mathrm{s}, P=0.1, T=298 \mathrm{~K}$ and $\eta$ (the viscosity of the medium $)=8.904 \times 10^{-4} \mathrm{~Pa}$ s. The others are noted elsewhere.

Figure 4 shows the frequency dependence of the relative permittivity of cell suspensions calculated at different $c_{\mathrm{a}}$. The dielectric spectra are the case for intact cells with the less conducting plasma membrane with $\kappa_{\mathrm{m}}=10^{-7} \mathrm{~S} / \mathrm{m}$. The spectrum for $c_{\mathrm{a}}=1$ $\mathrm{mM}$ includes the LF dispersion below $10 \mathrm{kHz}$, the $\mathrm{HF}$ dispersion between $0.1 \mathrm{MHz}$ and $10 \mathrm{MHz}$ and a very small dispersion above $10 \mathrm{MHz}$, which is so-called the $\delta$-dispersion. The intensity of the LF dispersion decreases slightly between 1 and $3 \mathrm{mM}$ and largely above $5 \mathrm{mM}$, whereas that of the HF dispersion increases with $c_{\mathrm{a}}$. If the frequency that corresponds to one-half of the dispersion intensity is taken as the characteristic frequency, that of LF dispersion is mostly independent of $c_{\mathrm{a}}$ and that of HF dispersion increases with $c_{\mathrm{a}}$. The simulation interprets the experimental results (Fig. 1) qualitatively although the LF dispersion is broader than that obtained experimentally.

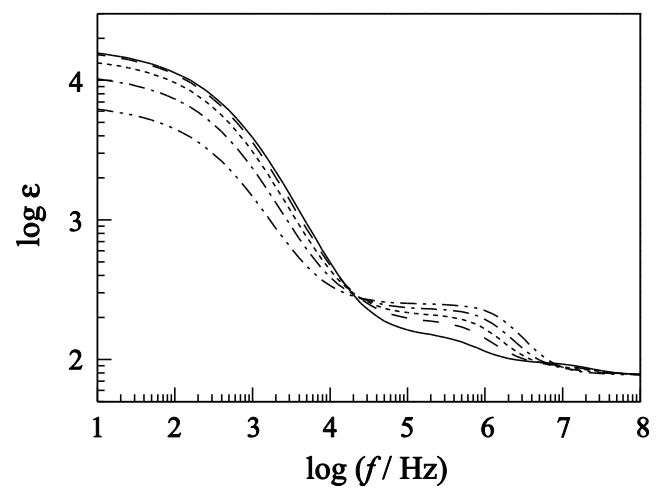

Fig. 4 Effects of the electrolyte concentration $c_{\mathrm{a}}$ of the external medium on the dielectric spectra (frequency $f$ dependence of relative permittivity $\varepsilon$ ) of intact cell suspensions. The dielectric spectra were calculated at $c_{\mathrm{a}} / \mathrm{mM}=1$ (solid line), 2 (broken line), 3 (dotted line), 5 (dashed-dotted line) and 10 (dashed-two dotted line). The parameter values used: $\sigma_{0}=0.1 \mathrm{C} / \mathrm{m}^{2}$, 
$\kappa_{\mathrm{m}}=10^{-7} \mathrm{~S} / \mathrm{m}$ and $\zeta=0.204 \mathrm{~V}($ for $1 \mathrm{mM}), 0.187(2), 0.176(3), 0.163$ (5) and $0.146(10)$.

The dielectric spectra of live and dead cells have been simulated by varying the membrane conductivity $\kappa_{\mathrm{m}}$ as shown in Fig. 5. The HF dispersion is unchanged from $\kappa_{\mathrm{m}}=0$ to $10^{-6} \mathrm{~S} / \mathrm{m}$, and decreases in intensity with increasing $\kappa_{\mathrm{m}}$ to diminish completely above $\kappa_{\mathrm{m}}=3 \times 10^{-4} \mathrm{~S} / \mathrm{m}$. Nevertheless, the LF dispersion is nearly independent of $\kappa_{\mathrm{m}}$ in agreement with the experimental results (Fig. 2).

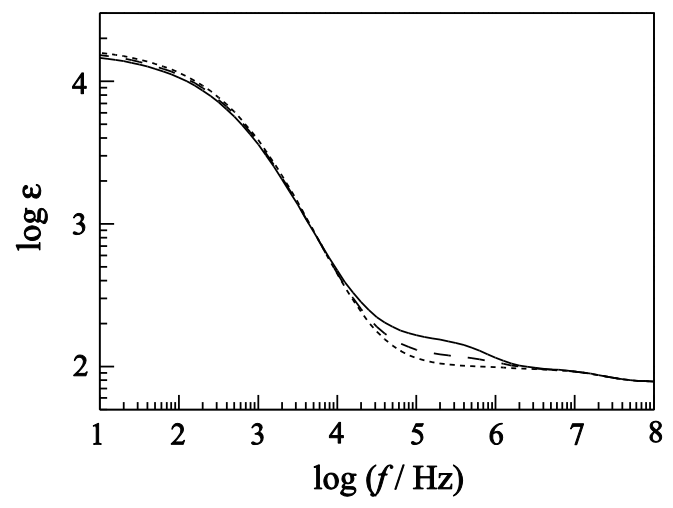

Fig. 5 Effects of the membrane conductivity $\kappa_{\mathrm{m}}$ on the dielectric spectra (frequency $f$ dependence of relative permittivity $\varepsilon$ ) of cell suspensions. The dielectric spectra were calculated with $\kappa_{\mathrm{m}} / \mathrm{S} \mathrm{m}^{-1}=10^{-7}$ (solid line), $10^{-4}$ (broken line) and $3 \times 10^{-4}$ (dotted line) when $\sigma_{0}=0.1 \mathrm{C} / \mathrm{m}^{2}$ and $c_{\mathrm{a}}=1 \mathrm{mM}$.

The similarity of the $\mathrm{pH}$ dependence of $\Delta \varepsilon_{\mathrm{L}}$ to the acid-base titration curve of $E$. coli cell suspensions implies that $\Delta \varepsilon$ L is proportional to the surface charge density $\sigma_{0}$ of the cells. Hence, the relationships between $\Delta \varepsilon_{\mathrm{L}}$ and $\sigma_{0}$ have been simulated for the case of the dead cells with $\kappa_{\mathrm{m}}=3 \times 10^{-4} \mathrm{~S} / \mathrm{m}$, and are shown in Fig. $6 \mathrm{a}$. The $\Delta \varepsilon_{\mathrm{L}}$ is proportional to $\sigma_{0}$ and the simulation is consistent with the experimental results.

The experimental results showed the peculiar relationships between $\Delta \varepsilon \mathrm{L}$ and $c_{\mathrm{a}}$, i.e., $\Delta \varepsilon_{\mathrm{L}}$ has a maximum around $c_{\mathrm{a}}=2 \mathrm{mM}$ and decreases rapidly with decreasing $c_{\mathrm{a}}$ below 1 $\mathrm{mM}$. The feature has been simulated by varying $c_{\mathrm{a}}$ at a constant charge density $\left(\sigma_{0}=0.1\right.$ $\mathrm{C} / \mathrm{m}^{2}$ ). Figure $6 \mathrm{~b}$ shows the $c_{\mathrm{a}}$ dependence of $\Delta \varepsilon \mathrm{L}$, in which the $\Delta \varepsilon \mathrm{L}$ has a maximum at $c_{\mathrm{a}}=1.5 \mathrm{mM}$ and a steep decrease at $c_{\mathrm{a}} \leq 1 \mathrm{mM}$. The theoretical calculation successfully interprets the experimental results shown in Fig. 3b. 

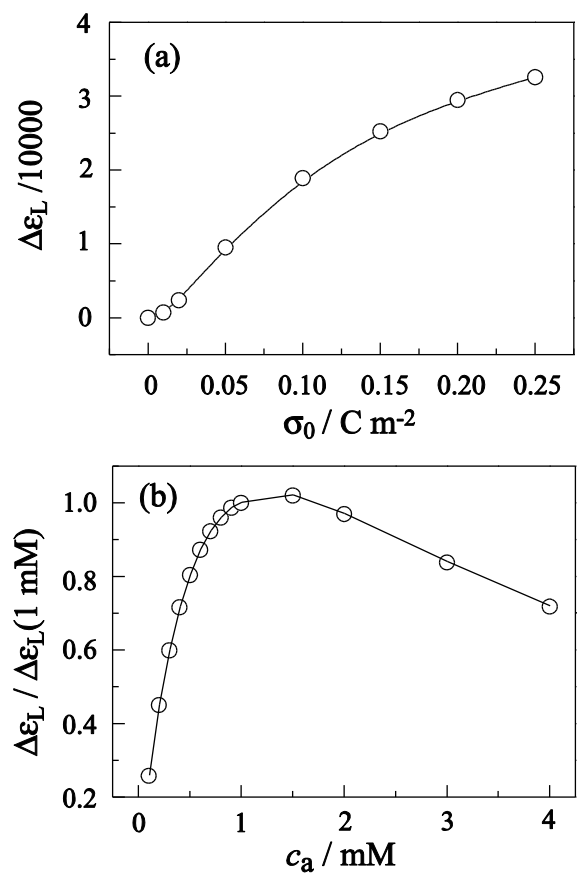

Fig. 6 The intensity $\Delta \varepsilon$ L of the LF dispersion as a function of (a) the surface charge density $\sigma_{0}$ and (b) the electrolyte concentration $c_{\mathrm{a}}$ of the external medium. Dielectric spectra were calculated with $\kappa_{\mathrm{m}}=3 \times 10^{-4} \mathrm{~S} / \mathrm{m}$, (a) $c_{\mathrm{a}}=1 \mathrm{mM}$ and (b) $\sigma_{0}=0.1 \mathrm{C} / \mathrm{m}^{2}$. In (b), $\Delta \varepsilon_{\mathrm{L}}$ is normalized at $c_{\mathrm{a}}=1 \mathrm{mM}$.

In conclusion, the simulation using the Grosse-Zimmerman model is consistent with the experimental results relating (1) the $c_{\mathrm{a}}$ dependence of $\Delta \varepsilon_{\mathrm{L}}$ and $\Delta \varepsilon_{\mathrm{H}}$, (2) the differences between the dielectric spectra of live and dead cells, and (3) the $\mathrm{pH}$ dependence of $\Delta \varepsilon_{\mathrm{L}}$. The model is too simplified for $E$. coli cells, but nevertheless provides the important features of the dielectric dispersion of $E$. coli cell suspensions.

\section{Appendix}

The quantities $\Delta d_{\mathrm{L}}, \tau_{\mathrm{L}}, d_{\mathrm{Lh}}$ and $S$ in Eq. (4) that have been given by Grosse and Zimmerman [19] are simplified by assuming a 1-1 electrolyte that has the same diffusion constant $D$ for the anion and cation.

$$
\Delta d_{\mathrm{L}}=-\frac{3}{2} S\left(\frac{R^{+}-R^{-}}{R^{+}+R^{-}+4}\right)^{2}
$$




$$
\begin{aligned}
& \tau_{\mathrm{L}}=\frac{S R_{\mathrm{c}}{ }^{2}}{2 D}, \\
& d_{\mathrm{Lh}}=\frac{R^{+}+R^{-}-2}{R^{+}+R^{-}+4}, \\
& S=\frac{2\left(R^{+}+R^{-}+4\right)}{\left(R^{+}+2\right)\left(R^{-}+2-U\right)+\left(R^{-}+2\right)\left(R^{+}+2-U\right)},
\end{aligned}
$$

where

$$
\begin{aligned}
& R^{ \pm}=\frac{1}{K_{\mathrm{D}} R_{\mathrm{c}}}\left[4\left(e^{\mp \tilde{\zeta} / 2}-1\right)(1+3 m) \pm 6 m \tilde{\zeta}\right], \\
& m=\frac{2 \varepsilon_{\mathrm{a}} \varepsilon_{0}}{3 \eta D}\left(\frac{R T}{F}\right)^{2}, \\
& U=\frac{48 m}{K_{\mathrm{D}} R_{\mathrm{c}}} \ln \left[\cosh \left(\frac{\tilde{\zeta}}{4}\right)\right] .
\end{aligned}
$$

The dimensionless zeta potential $\tilde{\zeta}$ is given by $\tilde{\zeta}=F \zeta /(R T)$ and $\eta$ is the viscosity of the medium. The reciprocal Debye screening length $K_{\mathrm{D}}$ is defined as $K_{\mathrm{D}}=\sqrt{2 F^{2} c_{\mathrm{a}} /\left(R T \varepsilon_{\mathrm{a}} \varepsilon_{0}\right)}$. The other symbols are the same as those described in section 3.4 . 


\section{References}

[1] H. Fricke, H. P. Schwan, K. Li and V. Bryson, Nature 177 (1956)134.

[2] H. P. Schwan, in J. H. Lawrence, C. A. Tobias (Eds.), Advances in Biological and Medical Physics, vol. 5, Academic Press, New York, 1957, p. 147.

[3] K. R. Foster and H. P. Schwan, in E. C. Polk and E. Postow (Eds.), Handbook of Biological Effects of Electromagnetic Fields, CRC Press, Boca Raton, 2nd edn., 1996, chapter 1.

[4] K. Asami, J. Non-Cryst. Solids, 305 (2002) 268.

[5] E. L. Carstensen, H. A. Cox, W. B. Mercer and L. A. Natale, Biophys. J., 5 (1965) 289.

[6] E. L. Carstensen, Biophys. J., 7 (1965) 493.

[7] E. L. Carstensen and R. E. Marquis, Biophys. J., 8 (1968) 536.

[8] R. E. Marquis and E. L. Carstensen, Spores, 6 (1975) 563.

[9] K. Asami, T. Hanai and N. Koizumi, Biophys. J., 31 (1980) 215.

[10] W. Bai, K. S. Zhao and K. Asami, Biophys. Chem., 122 (2006) 136.

[11] C. W. Einolf and E. L. Carstensen, Biophys. J., 9 (1969) 634.

[12] C. W. Einolf and E. L. Carstensen, Biophys. J., 13 (1973) 8.

[13] A. van der Wal, M. Minor, W. Norde, A. J. B. Zehnder and J. Lyklema, J. Colloid Interface Sci., 186 (1997) 71.

[14] C. Bot and C. Prodan, Eur. Biophys. J., 38 (2009) 1049.

[15] C. T. Bot and C. Prodan, Biophys. Chem., 146 (2010) 133.

[16] G. Schwarz, J. Phys. Chem., 66 (1962) 2636.

[17] S. S. Dukhin and V. N. Shilov, Dielectric Phenomena and the Double Layer in Disperse Systems, John Wiley \& Sons, New York 1974

[18] C. Grosse and A. V. Delgado, Curr. Opin. Colloid Interface Sci., 15 (2010) 145

[19] C. Grosse and V. Zimmerman, J. Phys. Chem. B, 109 (2005) 18088.

[20] V. Zimmerman and C. Grosse, J. Phys. Chem. B, 108 (2004) 12617.

[21] E. Gheorghiu, Phys. Med. Biol., 38 (1993) 979.

[22] E. Gheorghiu, J. Phys. A: Math. Gen., 27 (1994) 3883.

[23] C. Prodan and E. Prodan, J. Phys. D: Appl. Phys., 32 (1999) 335.

[24] E. Prodan, C. Prodan and J. H. Miller, Biophys. J., 95 (2008) 4174.

[25] A. Di Biasio, L. Ambrosone and C. Cametti, Biophys. J., 99 (2010) 163.

[26] A. Di Biasio and C. Cametti, Phys. Rev. E, 82 (2010) 021917.

[27] K. Asami, A. Irimajiri, T. Hanai, N. Shiraishi and K. Utsumi, Biochim. Biophys. Acta, 778 (1984) 559.

[28] K. Asami, Soft Matter, 8 (2012) 3250. 
[29] L. Fiksdal and I. Tryland, J. Appl. Microbiol. 87 (1999) 62.

[30] S. Baatout, P. De Boever and M. Mergeay, Ann. Microbiol. 55 (2005) 73.

[31] V. P. Harden and J. O. Harris, J. Bacteriol., 65 (1952) 198.

[32] R. E. Martinez, D. S. Smith, E. Kulczycki and F. G. Ferris, J. Colloid Interface Sci., 253 (2002) 130. 


\section{Figure legends}

Fig. 1 Frequency $f$ dependence of the relative permittivity $\varepsilon$ of $E$. coli cells suspended in $1(\circ), 3(\bullet), 6(\Delta)$ and $10(\Delta) \mathrm{mM} \mathrm{NaCl}$. The cell suspensions were prepared to have the same cell concentration. The best-fit curve (solid line) for the data with $1 \mathrm{mM} \mathrm{NaCl}$ is shown separately from the EP effect (broken line). Inset: an expanded view of the HF dispersion with the best-fit curves for the data with $1 \mathrm{mM}$ (solid line), $3 \mathrm{mM}$ (broken line), $6 \mathrm{mM}$ (dotted line) and $10 \mathrm{mM}$ (dashed-dotted line).

Fig. 2 Frequency $f$ dependence of the relative permittivity $\varepsilon$ for intact ( $\circ)$ and heat-treated $(\bullet)$ cells suspended in $1 \mathrm{mM} \mathrm{NaCl}$. The suspensions are prepared to have the same cell concentration. The solid lines are the best-fit curves calculated from Eq. (1), excluding the EP effect (dotted line). The HF dispersion (broken line) in intact cells is not seen in dead cells.

Fig. 3 Effects of (a) the $\mathrm{pH}$ and (b) $\mathrm{NaCl}$ concentration $c_{\mathrm{a}}$ of the medium on the intensity $\Delta \varepsilon$ of the LF dispersion. $\Delta \varepsilon$ is normalized at (a) $\mathrm{pH}$ 6.9-7.1 and at (b) $1 \mathrm{mM}$.

Fig. 4 Effects of the electrolyte concentration $c_{\mathrm{a}}$ of the external medium on the dielectric spectra (frequency $f$ dependence of relative permittivity $\varepsilon$ ) of intact cell suspensions. The dielectric spectra were calculated at $c_{\mathrm{a}} / \mathrm{mM}=1$ (solid line), 2 (broken line), 3 (dotted line), 5 (dashed-dotted line) and 10 (dashed-two dotted line). The parameter values used: $\sigma_{0}=0.1 \mathrm{C} / \mathrm{m}^{2}, \kappa_{\mathrm{m}}=10^{-7} \mathrm{~S} / \mathrm{m}$ and $\zeta / \mathrm{V}=0.204$ (for $1 \mathrm{mM}$ ), 0.187 (2), $0.176(3), 0.163$ (5) and $0.146(10)$.

Fig. 5 Effects of the membrane conductivity $\kappa_{\mathrm{m}}$ on the dielectric spectra (frequency $f$ dependence of relative permittivity $\varepsilon$ ) of cell suspensions. The dielectric spectra were calculated with $\kappa_{\mathrm{m}} / \mathrm{S} \mathrm{m}^{-1}=10^{-7}$ (solid line), $10^{-4}$ (broken line) and $3 \times 10^{-4}$ (dotted line) when $\sigma_{0}=0.1 \mathrm{C} / \mathrm{m}^{2}$ and $c_{\mathrm{a}}=1 \mathrm{mM}$.

Fig. 6 The intensity $\Delta \varepsilon_{\mathrm{L}}$ of the LF dispersion as a function of (a) the surface charge density $\sigma_{0}$ and (b) the electrolyte concentration $c_{\mathrm{a}}$ of the external medium. Dielectric spectra were calculated with $\kappa_{\mathrm{m}}=3 \times 10^{-4} \mathrm{~S} / \mathrm{m}$, (a) $c_{\mathrm{a}}=1 \mathrm{mM}$ and (b) $\sigma_{0}=0.1 \mathrm{C} / \mathrm{m}^{2}$. In (b), $\Delta \varepsilon_{\mathrm{L}}$ is normalized at $c_{\mathrm{a}}=1 \mathrm{mM} . \kappa_{\mathrm{m}}=3 \times 10^{-4} \mathrm{~S} / \mathrm{m}$ 